\title{
COMPETÊNCIAS PARA ITINERÁRIOS FORMATIVOS NO ENSINO PROFISSIONAL: UM ESTUDO PARA EGRESSOS DE ENSINO TÉCNICO DE UMA INSTITUIÇÃO DE ENSINO PROFISSIONAL
}

\author{
SKILLS FOR EDUCATIONAL ITINERARY IN PROFESSIONAL EDUCATION: A STUDY FOR TECHNICAL HIGH \\ SCHOOL TO PURSUE THEIR STUDIES IN A TECHNICAL COLLEGE COURSE
}

Luciano José Dantas ${ }^{1}$, Roberto Kanaane ${ }^{2}$

Submetido em: $28 / 04 / 2020$

Avaliado em: 28/09/2020

Aprovado em: 23/02/2021

\section{RESUMO}

O presente artigo teve por objetivo abordar, a partir do conceito de competências utilizado em educação profissional, a perspectiva de identificar um itinerário formativo destinado a alunos egressos de cursos técnicos para prosseguimentos de estudos em curso superiores de tecnologia. Como introdução, o conceito de competências foi abordado a partir dos autores Almeida (2017), Dias (2010), Lopez (2016), Marinho-Araújo (2015-2017) e Rabelo (2015). Adotou-se como ponto de partida a legislação brasileira pertinente à educação profissional visto sua relevância ao entendimento do itinerário formativo proposto pelos catálogos nacionais de cursos técnicos e de cursos superiores de tecnologia. A pesquisa foi de natureza aplicada e abordagem qualitativa; o método adotado foi descritivo conjugado ao método exploratório, envolvendo levantamento bibliográfico e documental. Nessa pesquisa foram feitas análises comparativas de três cursos técnicos e três cursos superiores de tecnologia com denominação similar e de mesmo eixo tecnológico. A primeira análise foi a verificação dos descritivos dos itens principais referentes aos cursos e os respectivos catálogos; a segunda análise foi a comparação de matrizes curriculares dos cursos de uma instituição pública. Essas análises permitiram identificar similaridades entre os cursos em relação à formação, sinalizando a possibilidade de se trabalhar com competências, implicando na revisão dos currículos dos cursos analisados.

PALAVRAS-CHAVE: Competências. Itinerários Formativos. Ensino Profissional.

\section{ABSTRACT}

The aim of this article is to approach, from the concept of skills that it used in professional education, the perspective of identifying the student's educational itinerary from a Technical High School to pursue their studies in a Technical College Course. As an introduction to the topic, the concept of competences was discussed through the authors Almeida (2017), Dias (2010), Lopez (2016), Marinho-Araújo (2015-2017) and Rabelo (2015. As a start point, the relevant Brazilian legislation on professional education was also mentioned in the study, given its relevance for understanding the subject training itinerary proposed by the national catalogs of technical courses and higher technology

\footnotetext{
${ }_{1}^{1}$ Possui graduação em Tecnologia Mecânica Modalidade Soldagem pela Fatec - Faculdade de Tecnologia de São Paulo (1998), especialização em Tecnologias na Educação pelo Centro Universitário Senac (2015) e Mestrado Profissional em Gestão e Desenvolvimento da Educação Profissional pelo Centro Paula Souza (2018). Atualmente é professor de ensino superior II em faculdades de tecnologia e coordenador de projetos no Centro Estadual de Educação Tecnológica Paula Souza, atuando como gestor pedagógico regional. Possui experiência profissional nas áreas de instrumentação industrial (válvulas de controle, válvulas On-Off, sistemas de monitoramento industriais, redes industriais) e transferência de fluidos (bombas hidráulicas, sistemas de dosagem química), atuando como tecnólogo mecânico em diversas funções. Correio eletrônico: luciano.dantas@fatec.sp.gov.br

${ }^{2}$ Psicólogo, Mestre e Doutor em - USP. Membro da Academia Paulista de Psicologia, ocupando a cadeira 21. Atuação em Programa de Mestrado Profissional em Gestão. Correio eletrônico: kanaanhe@gmail.com
} 
courses. The proposed research was of an applied nature and qualitative approach; there search methodology was descriptive in conjunction with the exploratory method, involving bibliographic and documentary survey. In this study, comparative analyzes of three technical high school courses and three Technical College Course of similar denomination with the same technological axis were made. The first analysis was the verification of the descriptions of the main items of the courses in their respective catalogs. The second analysis, the curriculum matrices of the courses of a public institution were compared. The proposed analyzes allowed us to identify similarities among the courses in relation to training, signaling the possibility of working with skills, implying a review of the curriculum of the analyzed courses.

KEYWORDS: Skills. Training Itineraries. Professional Education. 


\section{INTRODUÇÃO}

O investimento em educação profissional é uma necessidade premente em um país de tamanho continental como o Brasil. As diversas regiões, os diferentes polos de produção e as características de cada estado fazem com que as iniciativas de educação profissional, sejam em formação inicial e continuada estejam voltadas aos cursos técnicos e cursos superiores tecnológicos, alinhadas às demandas provenientes destes locais.

Considerando que uma boa parte dos investimentos são realizados por instituições públicas municipais, estaduais e federais, deve-se salientar que o que é aprendido em um nível de educação (inicial, técnico e superior) deveria ser/direcionado as formações posteriores para que o recurso público investido fosse mais bem aproveitado.

Para esse aproveitamento, pode-se considerar o conceito de competências, que é adotado em gestão de pessoas em ambientes corporativos, visando mensurar o desempenho profissional dos colaboradores de uma determinada companhia.

Nesse sentido a profissionalização requer, no contexto atual, a necessidade de implementar diretrizes e práticas voltadas ao desenvolvimento de competências sintonizadas com o processo formativo e com as demandas do mercado.

Em função do exposto, questiona-se em que medida há similaridades de competências desenvolvidas nos cursos técnicos que podem ser incorporadas nos cursos superiores tecnológicos, voltadas aos itinerários formativos no ensino profissional?

Consequentemente tem-se como objetivo desse estudo: identificar e caracterizar as competências de cursos técnicos e superiores tecnológicos de mesmo eixo e mesma nomenclatura visando o aproveitamento do que foi adquirido pelos discentes frente ao itinerário formativo no ensino profissional, em sua continuidade de estudos.

\section{FUNDAMENTAÇÃO TEÓRICA Competências}

Um dos desafios da educação profissional refere-se ao estudo das competências. Espera-se que os alunos egressos dos cursos técnicos e tecnológicos oferecidos nas diversas instituições presentes no Brasil sejam pre- parados para o exercício profissional, de acordo com os requisitos dos catálogos nacionais dos cursos.

Tem-se observado que muitos discentes que frequentam esses cursos já possuem atributos de competências, entre elas as técnicas, visto que são profissionais inseridos no mercado de trabalho formal e informal, exercendo funções diversas.

Esses discentes foram denominados de "alunos-trabalhadores" por Fischer e Franzoi (2009), cujo trabalho discutiu a formação humana e profissional dos mesmos. As pesquisadoras consideraram que, de uma forma geral, tais discentes não se beneficiam dos conhecimentos adquiridos em função da forma com que os currículos dos cursos são construídos, visto que os saberes institucionalizados muitas vezes desconsideram as vivências destes no mercado em que atuam, o que tem ocasionado uma aprendizagem não significativa.

Segundo Ausubel (2003), na aprendizagem significativa há vantagens essenciais em relação à aprendizagem memorística, sendo que o conhecimento que se adquire de maneira significativa é retido e lembrado por mais tempo, aumenta a capacidade de aprender outros conteúdos de uma maneira mais fácil e facilita a aprendizagem seguinte - a "reaprendizagem".

Outro aspecto relevante a ser acrescido nessa discussão é a mudança vertiginosa do mundo do trabalho, com o advento do conceito de Indústria 4.0 e seus pilares, como a Internet das Coisas, Big Data, Manufatura Aditiva e outros elementos. As alterações cada vez mais profundas e a revolução tecnológica exigem/um outro perfil de profissional, mais adequado a essa realidade e com novas competências, que necessitam ser acompanhadas pelas instituições de ensino em suas concepções curriculares. Observa-se que o tempo de resposta a essas mudanças não é o existente nas instituições de ensino, o que tem gerado um gap de formação dos egressos.

Cordão (2018) salientou em seu trabalho a necessidade de uma completa revisão de currículos, desde a educação básica até a educação profissional, procurando dessa maneira atender a um novo perfil de trabalhador, que necessita ter ampliada a capacidade de raciocínio, autonomia intelectual, pensamento crítico, espírito empreendedor e capacidade de resolver problemas em sua atuação.

A aquisição de competências já permeia a discussão dos currículos escolares, com a ressalva de que a 
velocidade com que os currículos são adequados a essas necessidades não atende plenamente o momento de mudanças em que vivemos.

Dias (2010) concebeu competência sob a ótica das capacidades, habilidades, aptidões, potencialidades e conhecimentos. A autora sustentou que a competência integra e coordena um conjunto de esquemas de percepção, de pensamento, de avaliação e de ação voltados para gerar atitudes eficazes em determinados contextos.

Essa concepção de competência, ainda segundo a autora, determina que a instituição de ensino incorpore diretrizes para uma abordagem de ensino/aprendizagem voltadas ao trabalho por meio de problemas, utilizando novas metodologias de ensino, principalmente a aprendizagem por projetos. Desse modo a meta da instituição deve ser de desenvolvimento de competências e de permitir ao egresso alcançar sucesso pessoal e profissional, superando a visão tradicional em ensinar conteúdo.

Marinho-Araújo e Almeida (2017) conceberam competência como um constructo teórico prático, possuindo múltiplas dimensões e vários significados. Essas dimensões são alteradas constantemente pelas mudanças nos contextos sócio-histórico, econômico e cultural vigente nas últimas décadas, influenciando as relações laborais e alterando os perfis profissionais a partir dos anos 90 .

Com a finalidade de atender a tais alterações, os referidos autores analisaram que uma ferramenta essencial ao planejamento da formação na educação superior refere-se ao trabalho docente focado no desenvolvimento de competências, implicando que essa estratégia seja fundamental para a construção de um perfil educacional e profissional adequado as demandas de mercado contemporâneo.

Evidenciam-se que os itinerários formativos presentes na educação profissional necessitam considerar as competências adquiridas pelo discente, seja em uma educação formal feita anteriormente, ou em um ambiente laboral. Consequentemente surge a necessidade em apreender e avaliar as competências adquiridas pelos discentes no seu percurso formativo.

Essa questão aborda a prerrogativa de que o itinerário de formação de um aluno deve considerar suas competências anteriores para o aproveitamento das mesmas sob o enfoque de um currículo escolar, seja o de ensino técnico ou superior tecnológico.

Segundo Marinho-Araújo e Rabelo (2015), o processo de avaliação educacional apresenta múltiplos sentidos que foram produzidos na interdependência entre o aprendizado de conhecimentos e o desenvolvimento de competências. Neste sentido, os autores sinalizam que as mudanças pedagógicas das diretrizes curriculares da educação superior vêm evidenciando a necessidade de a pesquisa educacional apreender a trajetória de formação educativa, as competências adquiridas e quais seriam as formas de se identificar tais conhecimentos nos discentes.

Para tal feito, verifica-se que a definição de competência deve ser implementada nas instituições de ensino, visto que sua complexidade e amplitude não possibilita que um só método de apreensão seja suficiente para definir a aquisição de uma determinada competência por um discente, considerando-se que o conceito contempla aspectos cognitivos e também processos intersubjetivos, afetivos e socioculturais, implicando em ações coletivas da direção, coordenação e corpo docente dessas instituições.

Lopez (2016) identificou que o conceito de competências engloba conhecimentos, habilidades e atitudes, embora mudanças vem se constituindo nos últimos vinte anos, tendo sido substituído por um modelo que avalia os colaboradores no mundo corporativo, observando suas competências técnicas (compostas por conhecimentos e habilidades), competências comportamentais e essências (composta pelas atitudes) e consequentemente os resultados decorrentes.

O referido autor informou que as competências técnicas são aquelas necessárias ao exercício de determinado cargo ou função nas empresas, que podem ser segmentadas em grupos; as competências comportamentais são aquelas relacionadas às aptidões ou traços da personalidade; as competências essenciais são os pequenos grupos de valores ou princípios considerados vitais para as empresas e os resultados são os que foram alcançados na execução ou desempenho efetivo no ambiente de trabalho.

Lopez (2016) sugeriu em seu trabalho a utilização de uma escala para mensurar as competências de determinado indivíduo quando submetido a uma avaliação de competências. Essa escala contempla níveis progressivos, numerados de 1 a 4 , passando pelos níveis básico, médio, alto e avançado. 0 quadro 1 relaciona os 
níveis e uma descrição sumária desse nível:

Quadro 1: Escala de avaliação de competências

\begin{tabular}{|c|c|c|}
\hline Nivel 1 & Básico & Indica noção do assunto. Sabe o que é, mas não é capaz de operar. \\
\hline Nivel 2 & Médio & Competência parcial. Faz o simples, não o complexo. \\
\hline Nivel 3 & Alto & Bastante completo. Só não lida com situações atípicas. \\
\hline Nivel 4 & Avançado & Expert. Reconhecido até fora da empresa como destaque. \\
\hline
\end{tabular}

Fonte: Os autores.

Após essa reflexão sobre as concepções de competências, buscou-se traçar um panorama da legislação da educação profissional no Brasil, suas nuances em relação aos níveis de formação e as suas principais características, considerando a trajetória de formação e as competências adquiridas nos níveis técnicos e tecnológicos.

\section{Legislação da Educação Profissional no Brasil}

O decreto $n^{\circ} 5.154$ da Presidência da República do Brasil de 23 de julho de 2004 regulamentou o parágrafo $2^{\circ}$ do artigo 36 e os artigos 39,40 e 41 da lei $n^{\circ} 9.394$, de 20 de dezembro de 1996, que estabeleceu as diretrizes e bases da educação nacional. Nesse decreto foram determinadas como seriam desenvolvidas as modalidades de educação profissional, sendo consideradas os seguintes níveis conforme seu Artigo $1^{\circ}$ :

I - Qualificação profissional, inclusive formação inicial e continuada de trabalhadores;

II - Educação profissional técnica de nível médio;

III - Educação profissional tecnológica de graduação e de pós-graduação.

Ainda em seu texto, o decreto considerou em seu artigo $2^{\circ}$ que a educação profissional observaria as premissas de serem organizadas por áreas profissionais, articuladas através de esforços das áreas de educação, trabalho e emprego, ciência e tecnologia, mantendo a centralidade do trabalho como princípio educativo e a indissociabilidade entre teoria e prática.

Deve-se considerar que há um certo equívoco em estabelecer que um curso de graduação tecnológico é uma consequência, ou uma evolução, do curso técnico de nível médio. A própria Lei de Diretrizes e Bases da Educação (Lei 9.394 de 20/12/1996) considerou como educação superior os cursos sequenciais, os de graduação e pós-graduação e, sendo o curso tecnológico uma graduação, pode-se afirmar que o mesmo está nessa classificação, distintamente de seus objetivos em relação aos cursos de licenciatura e bacharelado.

O critério para de se diferenciar um curso superior de tecnologia de um curso técnico de nível médio passa pelo de maior densidade tecnológica, segundo análise de Machado (2008), onde se pode compará-lo com cursos superiores também densos de tecnologia, como é o caso dos bacharelados. A autora também sustentou que o tecnólogo é uma categoria de trabalhador qualificado, atendendo a demanda de surgimento de novas profissões e ao dinamismo do sistema produtivo.

Zakon, Do Nascimento e Szanjberg (2003) salientaram que o tecnólogo enfrenta desafios, visto que os limites de atuação dos egressos dos cursos técnicos e dos cursos de bacharelado em engenharia são bem conhecidos há mais de um século. Por outro lado, os autores perceberam que os cursos de tecnologia implantados na época, e que foram objeto de estudo na pesquisa, apresentavam um déficit na formação, principalmente nas disciplinas de base científica, levando em consideração as concepções curriculares da época. Essa constatação, segundo os pesquisadores, tenderia a limitar a evolução profissional dos tecnólogos ao se defrontarem com as novas tecnologias.

Dos Santos e Jiménez (2009) analisaram a legislação dos cursos superiores tecnológicos, sua origem e criticaram a formação, pois entenderam que a concepção desses transmitiu a ideia de cursos mais rápidos, mais ágeis e mais curtos e, ainda segundo os estudiosos, mais sintéticos em termos de conteúdo em relação ao bacharelado. Destacaram também na pesquisa a perspectiva do curso superior de tecnologia de garantir a qualificação da mão-de-obra frente à inserção das avançadas tecnologias no processo produtivo no Brasil, visando resolver o problema do desemprego com a ampliação e acesso ao ensino superior.

A análise comparativa proposta nesse estudo, entre os dois modelos de educação profissional, técnica e tecnológica, permitiu que as diferenças fundamentais entre os cursos sejam avaliadas. Desta forma, considerou-se como exemplos cursos de mesmos eixos e seus respectivos catálogos do Ministério da Educação (MEC).

O Catálogo Nacional de Cursos Técnicos (CNCT), cuja $3^{\text {a }}$ edição foi publicada em 2016, é um documento elaborado pelo MEC que organizou a oferta de cursos técnicos, no que diz respeito às denominações, a carga horária mínima de cada curso, o perfil profissional 
de conclusão, o campo de atuação do profissional e as ocupações associadas à Classificação Brasileira de Ocupações (CBO); normas associadas ao exercício profissional, possibilidades de certificação intermediária em cursos de qualificação profissional, de formação continuada em cursos de especialização e de verticalização para cursos de graduação no itinerário formativo. Além dos itens explicitados, o documento informa às instituições de ensino a infraestrutura mínima requerida para oferecimento dos cursos.

O MEC também elaborou um catálogo para os cursos superiores de tecnologia. O Catálogo Nacional de Cursos Superiores de Tecnologia (CNCST), cuja $3^{a}$ edição foi publicada em 2016,é um documento que elencou as denominações e respectivos descritivos dos Cursos Superiores de Tecnologia, no que diz respeito ao perfil profissional de conclusão, infraestrutura mínima requerida para a oferta do curso, carga horária mínima do curso, campo de atuação profissional, ocupações CBO associadas, além das possibilidades de prosseguimento de estudos na Pós-Graduação, tanto lato sensu quanto stricto sensu. O catálogo visou consolidar as denominações e instituir um referencial sobre cursos superiores de tecnologia capaz de balizar os processos administrativos de regulação e as políticas e procedimentos de avaliação desses cursos.

\section{METODOLOGIA}

O estudo, do ponto de vista de sua natureza, foi uma pesquisa aplicada, pois objetivou gerar conhecimentos voltados a possíveis soluções de um problema específico, conforme Kauark, Manhães e Medeiros (2010). A abordagem do problema implicou no enfoque qualitativo e a análise dos dados caracterizou-se como sendo descritiva, ainda conforme os autores Kauark, Manhães e Medeiros (2010). Teve como foco o método descritivo conjugado ao método exploratório.

O método descritivo segundo Gil (2008) tem como objetivo primordial a descrição das características de determinada população ou fenômeno e o método exploratório tem como objetivo proporcionar uma visão geral, de tipo aproximativo, acerca de determinado fato, habitualmente envolvendo levantamento bibliográfico e documental, que foram as técnicas adotadas nesse estudo.

A pesquisa teve como proposta a comparação de cursos técnicos e cursos superiores de tecnologia, presentes nos respectivos catálogos do MEC e que possuem eixos tecnológicos e denominação similares.

A primeira comparação considerou as características dos cursos apresentados nos respectivos catálogos do MEC (2016), onde verificou-se os descritivos dos itens principais dos cursos técnicos e cursos superiores tecnológicos escolhidos, com intuito de identificar as similaridades de formação e apontar as diferenças entre os níveis. A segunda comparação considerou os mesmos cursos descritos acima, porém foram relacionadas as matrizes curriculares dos cursos técnicos e cursos superiores de tecnologia oferecidos por uma instituição de ensino público estadual, visando identificar competências adquiridas no nível técnico que poderiam ser aproveitadas no nível superior tecnológico.

Foram selecionados os seguintes cursos para análise e comparação, conforme quadro 2:

Quadro 2: Cursos técnicos e superiores de tecnologia selecionados

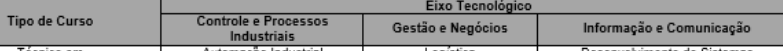

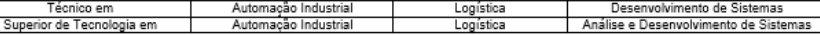

Fonte: Os autores

\section{DISCUSSÃO}

Comparações entre cursos técnicos e cursos superiores de tecnologia de acordo com os respectivos catálogos do MEC (2016)

Para uma comparação entre o perfil de cursos técnicos e cursos superiores de tecnologia, levou-se em consideração as características informadas nos respectivos catálogos publicados pelo MEC (2016), sendo adotado para o curso técnico o Catálogo Nacional de Cursos Técnicos e para o curso superior de tecnologia adotou-se o Catálogo Nacional de Cursos Superiores de Tecnologia, ambas edições de 2016.

Foram considerados como referência nessa primeira análise comparativa três cursos de denominação similar e de mesmo eixo tecnológico, visando verificar os descritivos dos itens principais dos cursos técnicos e cursos tecnológicos escolhidos. Os primeiros cursos analisados foram o curso técnico em Automação Industrial e o curso superior de tecnologia em Automação Industrial, que são cursos do eixo "Controle e Processos 
Industriais". O quadro 3 apresentou as características do curso técnico e do curso superior de tecnologia de acordo com o que se verificou nos catálogos publicados pelo MEC:

Quadro 3: Comparativo entre cursos Técnico e Superior de Tecnologia em Automação Industrial

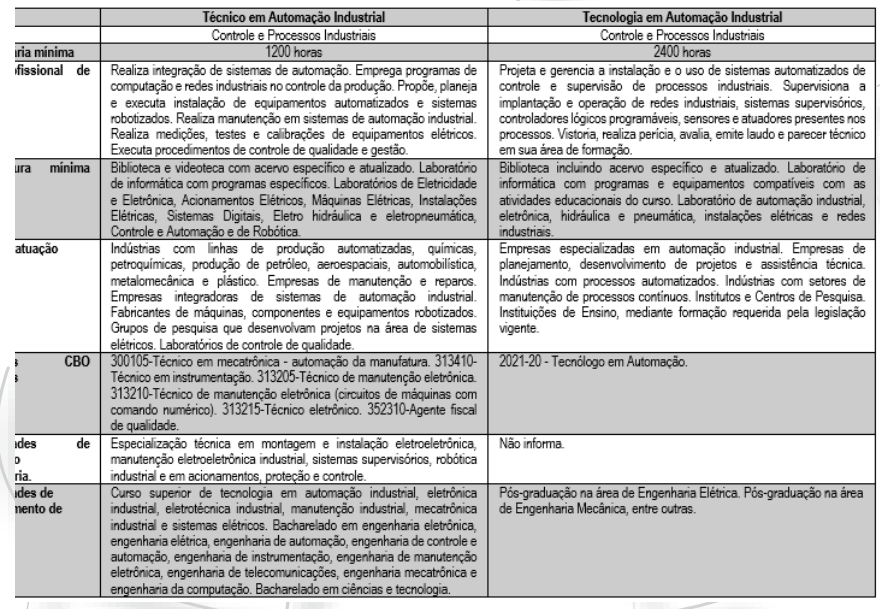

Fonte: Elaborado pelos autores, baseado no Catálogo Nacional de Cursos Técnicos (2016) e Catálogo Nacional de Cursos Superiores de Tecnologia (2016).

O curso técnico em Logística e o curso superior de tecnologia em Logística foram analisados segundo os critérios apresentados. Esses cursos são do eixo "Gestão e Negócios". O quadro 4 apresentou as características do curso técnico e do curso superior de tecnologia de acordo com o que se verificou nos catálogos publicados pelo MEC:

Quadro 4: Comparativo entre cursos Técnico e Superior de Tecnologia em Logística

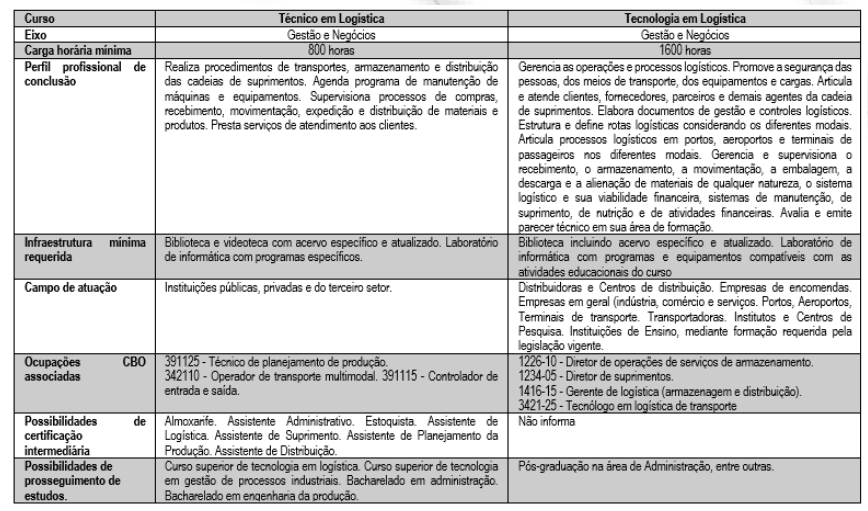

Fonte: Elaborado pelos autores, baseado no Catálogo
Nacional de Cursos Técnicos (2016) e Catálogo Nacional de Cursos Superiores de Tecnologia (2016).

O curso técnico em Desenvolvimento de Sistemas e o curso superior de tecnologia em Análise e Desenvolvimento de Sistemas, do eixo "Informação e Comunicação" foram analisados. Segue as características desses cursos de acordo com o que se verificou nos catálogos publicados pelo MEC:

Quadro 5: Comparativo entre cursos Técnico em Desenvolvimento de Sistemas e Superior de Tecnologia em Análise e Desenvolvimento de Sistemas

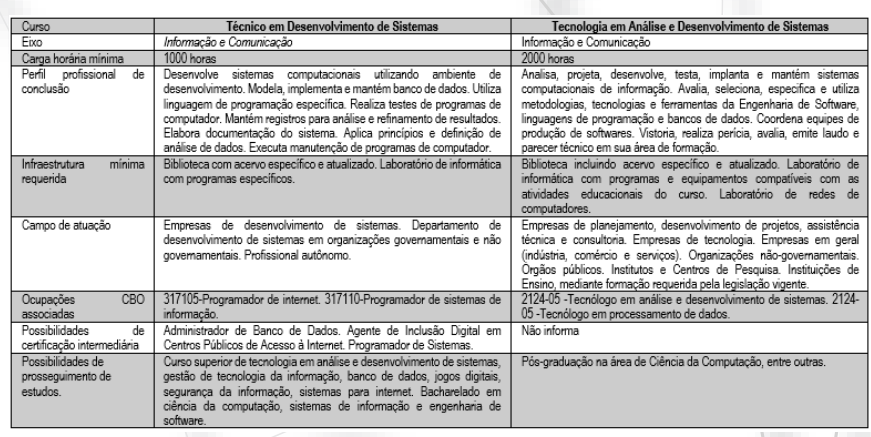

Fonte: Elaborado pelos autores, baseado no Catálogo Nacional de Cursos Técnicos (2016) e Catálogo Nacional de Cursos Superiores de Tecnologia (2016).

A análise dos três conjuntos de cursos técnicos e superiores de tecnologia permitiu identificar inicialmente as seguintes diferenças fundamentais entre os tipos de cursos, conforme quadro 6 abaixo:

Quadro 6: Análise das diferenças entre os cursos técnicos e superiores de tecnologia de acordo com as informações dos catálogos CNCT e CNCST

\begin{tabular}{|c|c|}
\hline Item & Análise \\
\hline Carga horária mínima: & $\begin{array}{l}\text { Os cursos técnicos possuem uma carga horária mínima } \\
\text { requerida como mínima para os cursos tecnológicos. }\end{array}$ \\
\hline Perfil profissional de conclusão: & $\begin{array}{l}\text { Os cursos tecnológicos concebem o profissional no patamar de supervisor ou gerente dos } \\
\text { procoessos produtivos de sua área de formaçâa, enquanto que o curso técnico indica funçōes } \\
\text { de ordem produtiva aos egressos dessa formaçâa. }\end{array}$ \\
\hline Intrat & oratórios requeridos săo compativeis. \\
\hline Campo de atuação: & $\begin{array}{l}\text { Observou-se que os dois profissionais terão o mesmo destino depois de forma } \\
\text { tecnólogos poderão se dedicar ao ensino, mediante formaçâo requerida } \\
\text { vigente. }\end{array}$ \\
\hline Ocup & $\mathrm{Ca}$ \\
\hline $\begin{array}{l}\text { Possibilidades } \\
\text { intermediária: }\end{array}$ & 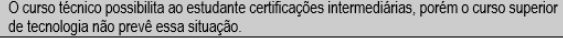 \\
\hline $\begin{array}{l}\text { Possibilidades de prosseguim } \\
\text { estudos: }\end{array}$ & $\begin{array}{l}\text { O curso superior de tecnologia possibilita ao egresso estudo de pós-graduação nas áreas } \\
\text { correlatas de sua formaçâo. O curso técnico sugere aos alunos prosseguimento de estudos } \\
\text { em cursos de tecnologia ou bacharelado na ârea de formaçâo. }\end{array}$ \\
\hline
\end{tabular}

Fonte: Elaborado pelos autores, baseado no Catálogo Nacional de Cursos Técnicos (2016) e Catálogo Nacional de Cursos Superiores de Tecnologia (2016). 
Comparações entre cursos técnicos e cursos superiores de tecnologia de acordo com os planos de curso e planos pedagógicos de uma instituição pública de ensino profissional

Para subsidiar esse estudo, escolheu-se uma instituição pública de ensino profissional que oferece cursos técnicos e cursos superiores de tecnologia, onde foram coletadas as informações das matrizes curriculares dos cursos em seus planos de cursos e planos pedagógicos. Conforme informações do sitio da entidade que foi objeto dessa pesquisa, a mesma é uma autarquia estadual, vinculada à Secretaria de Desenvolvimento Econômico e está presente em 321 municípios, administrando 223 Escolas Técnicas e 73 Faculdades de Tecnologia. Segundo o sitio eletrônico da instituição, possui mais de 297 mil alunos em cursos técnicos de nível médio e cursos superiores tecnológicos.

A segunda comparação feita nesse estudo possibilitou relacionar as matrizes curriculares dos cursos técnicos e cursos superiores de tecnologia escolhidos na primeira análise utilizando as matrizes dos cursos técnicos modulares e dos cursos superiores de tecnologia oferecidos por essa instituição pública de ensino profissional.

As tabelas1, 2, 3, 4, 5 e 6 seguintes demonstraram as matrizes curriculares dos cursos escolhidos para análise. Classificou-se, a partir das matrizes curriculares, para cada disciplina o tipo a qual ela está relacionada classificando-as como:

- Básicas: disciplinas de formação geral do aluno, geralmente relacionadas às áreas de matemática, português, inglês, física, química;

- Profissionais: disciplinas de cunho profissionalizante, relacionadas com o eixo tecnológico do curso;

- Gestão: disciplinas de formação complementar relacionadas com a área de gestão;

- Transversais: disciplinas de formação complementar que abordam temas específicos.

As tabelas agruparam as disciplinas de acordo com as classificações acima e apresentaram as cargas horárias totais de teoria e prática indicada nas matrizes curriculares. Como resumo, apresentou-se para cada curso os totais de aulas teóricas, aulas práticas e o total de aulas por curso.

A tabela 1 demonstrou a matriz curricular do curso superior de tecnologia em Automação Industrial oferecido pela instituição, de acordo com as considerações acima:
Tabela 1: Matriz curricular do curso superior de Tecnologia em Automação Industrial

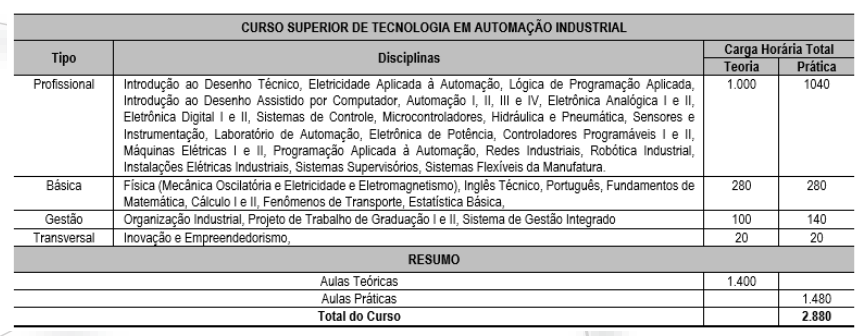

Fonte: Elaborado pelos autores.

A tabela 2destacou a matriz curricular do curso Técnico Modular em Automação Industrial:

Tabela 2: Matriz curricular do curso Técnico Modular em Automação Industrial

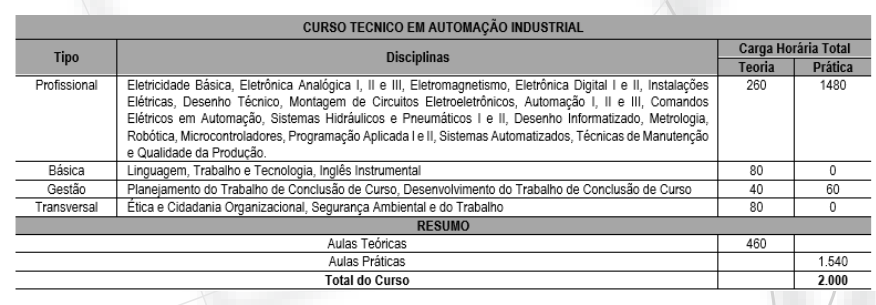

Fonte: Elaborado pelos autores.

Verificou-se, na análise comparativa das matrizes do curso Técnico Modular em Automação Industrial e o curso superior de Tecnologia em Automação Industrial oferecidos pela instituição, que o curso superior de tecnologia oferece uma carga horária dividida de aulas teóricas (49\% da carga horária) e aulas práticas (51\% da carga horária); por outro lado o curso técnico é predominantemente elaborado com aulas práticas $(77 \%$ do total). Observou-se também que a carga horária total do curso superior de Tecnologia em Automação Industrial correspondente a $44 \%$ mais do que o curso Técnico Modular em Automação Industrial.

Evidenciou-se nas disciplinas profissionais dos dois cursos nomenclaturas similares, que permitiu uma verificação de competências adquiridas no curso técnico visando o aproveitamento no curso superior de tecnologia. Em relação às cargas horárias, as disciplinas básicas no curso superior eram sete (7) vezes maiores do que as oferecidas no curso técnico. As disciplinas de gestão no curso superior de tecnologia visavam à formação do egresso em áreas de organização industrial e 
no curso técnico se resumiam a gestão do trabalho de conclusão de curso. As disciplinas transversais estão direcionadas ao empreendedorismo no curso superior de tecnologia, enquanto que no curso técnico abordavam questões relacionadas à ética e segurança.

A tabela 3 apresentou a matriz curricular do curso superior de Tecnologia em Logística oferecido pela instituição, considerando os mesmos critérios utilizados na análise anterior:

Tabela 3: Matriz curricular do curso superior de Tecnologia em Logística

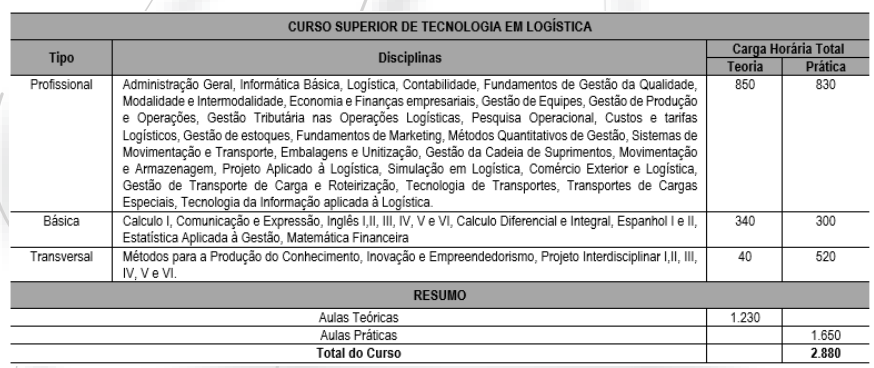

Fonte: Elaborado pelos autores.

A tabela 4 destacou a matriz curricular do curso Técnico Modular em Logística:

Tabela 4: Matriz curricular do curso Técnico Modular em Logística

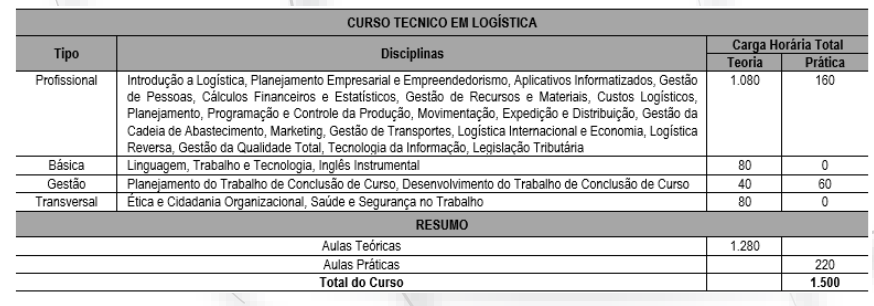

Fonte: Elaborado pelos autores.

Verificou-se, na análise comparativa das matrizes do curso Técnico Modular em Logística e o curso superior de Tecnologia em Logística, que o curso superior oferece uma carga horária dividida entre aulas teóricas ( $47 \%$ da carga horária) e aulas práticas ( $57 \%$ da carga horária) enquanto que o curso técnico é predominantemente elaborado com aulas teóricas ( $85 \%$ do total). A carga horária total do curso superior de tecnologia em Logística é $92 \%$ maior do que o curso técnico.

Assim como na análise anterior, constatou-se nas disciplinas profissionais de ambos os cursos nomenclaturas similares, que permite uma verificação de competências adquiridas no curso técnico para aproveitamento no curso superior de tecnologia. A análise das cargas horárias permitiu verificar que as horas dedicadas às disciplinas básicas no curso superior de tecnologia corresponde a oito (8) vezes mais do que as referentes ao curso técnico.

Por se tratarem de cursos do eixo de gestão, as disciplinas proporcionam uma formação como gestor de empresas no curso superior de tecnologia, assim como no curso técnico. Verificou-se que as disciplinas transversais estão mais direcionadas ao empreendedorismo e aos projetos integradores no curso superior de tecnologia, enquanto que no curso técnico abordam questões relacionadas à ética e segurança.

A tabela 5 sinalizou a matriz curricular do curso superior de Tecnologia em Análise e Desenvolvimento de Sistemas oferecido pela instituição, considerando os mesmos critérios utilizados nas análises anteriores:

Tabela 5: Matriz curricular do curso superior de Tecnologia em Análise e Desenvolvimento de Sistemas

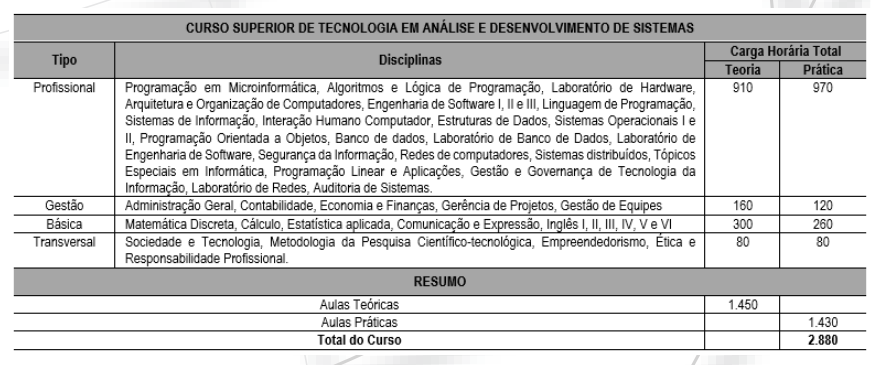

Fonte: Elaborado pelos autores.

A tabela 6 apresentou a matriz curricular do curso Técnico Modular em Desenvolvimento de Sistemas:

Tabela 6: Matriz curricular do curso Técnico Modular em Desenvolvimento de Sistemas

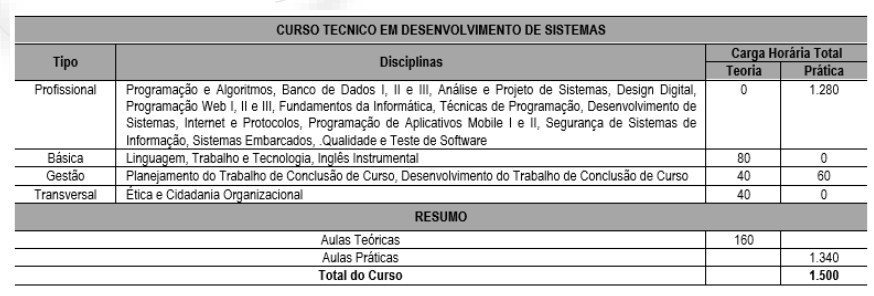

Fonte: Elaborado pelos autores. 
Verificou-se na análise comparativa das matrizes do curso Técnico Modular em Desenvolvimento de Sistemas e o curso superior de Tecnologia em Análise e Desenvolvimento de Sistemas que o curso superior oferece uma carga dividida entre aulas teóricas $(50,3 \%$ da carga horária) e aulas práticas ( $49,7 \%$ da carga horária); o curso técnico é predominantemente elaborado com aulas práticas ( $89 \%$ do total), sendo a carga horária das disciplinas profissionais prevista com $100 \%$ de atividades práticas.

Identificou-se que a carga horária total do curso superior de Tecnologia em Análise e Desenvolvimento de Sistemas é $92 \%$ maior do que o curso técnico modular. Assim como nas análises anteriores, constatou-se disciplinas profissionais dos dois cursos com nomenclaturas similares, que permite uma verificação de competências adquiridas para aproveitamento do egresso do curso técnico no curso superior. A análise das cargas horárias permitiu verificar que as horas dedicadas às disciplinas básicas no curso superior de tecnologia correspondem a sete (7) vezes mais do que as oferecidas no curso técnico.

As disciplinas de gestão no curso superior de tecnologia visam à formação do egresso em áreas de administração e no técnico se referem a gestão do trabalho de conclusão de curso. Evidenciou-se também que as disciplinas transversais estão mais direcionadas a questões de sociedade e tecnologia, empreendedorismo, ética e responsabilidade profissional no curso superior de tecnologia enquanto que no curso técnico abordam questões ligadas à ética.

\section{CONSIDERAÇÕES FINAIS}

Pode-se considerar que a análise realizada nesse estudo, quanto ao perfil dos cursos técnicos e dos cursos superiores de tecnologia, descritos nos catálogos publicados pelo MEC, permitiu identificar similaridades entre os cursos, no que diz respeito ao perfil profissional, a infraestrutura indicada para as instituições de ensino e o campo de atuação. Nesse aspecto, pode-se conceber um itinerário formativo para os egressos dos cursos técnicos, aproveitando as competências adquiridas nessa formação quanto a inserção no ensino superior, desde que seja caracterizado como mesmo eixo e mesma denominação de cursos.

Salienta-se, entretanto, que esse estudo está limitado aos cursos citados, que são oferecidos nas escolas e faculdades da instituição pública de ensino profissional utilizada como referência, podendo se estender a outros cursos pertencentes aos catálogos do MEC que tem a mesma denominação, e também a outras instituições que ofereçam cursos técnicos e cursos superiores tecnológicos.

A análise dos planos de curso e planos pedagógicos dos cursos técnicos e dos cursos superiores de tecnologia permitiu a identificação de similaridade de formação, principalmente nas disciplinas de cunho profissionalizante, que devem ser consideradas como competências adquiridas pelo estudante no nível técnico e incorporadas a matriz curricular do curso superior de tecnologia.

Percebe-se também que esse aproveitamento de estudos deve ser objeto de uma reformulação dos currículos dos cursos técnicos e superiores de tecnologia, que necessitam ser construídos com bases em competências e resultados não somente técnicos, mas também levando em consideração as comportamentais, as essenciais, implicando nos resultados de uma formação completa.

Essa construção curricular pode permear uma nova realidade na educação profissional, que deverá estabelecer itinerários formativos ao discente em instituições de educação profissional que ofereçam todos os níveis e que estejam em consonância com os anseios do mercado a que se destinam esses egressos.

Estudos posteriores poderão subsidiar a ampliação desta proposta, conforme a perspectiva de qualificação e profissionalização necessária a otimização, quanto a formação de profissionais aderentes as demandas do mercado de trabalho e da sociedade de maneira geral.

\section{REFERÊNCIAS}

AUSUBEL, D. P. Aquisição e retenção de conhecimentos: uma perspectiva cognitiva. Lisboa: Editora Plátano, 2003.

BRASIL. Decreto n. 5.154, de 23 de julho de 2004. Regulamenta o parágrafo $2^{\circ}$ do art. 36 e os arts. 39 a 41 da Lei $n^{\circ}$ 9.394, de 20 de dezembro de 1996. Diário Oficial da União, Brasília, 26 jul. 2004b. Disponível em: <http:// www.planalto.gov.br/ccivil_03/_ato2004-2006/2004/decreto/d5154.htm> Acesso em: 20 ago. 2019. 
BRASIL. Lei nº 9394 de 20 de dezembro de 1996. Estabelece as diretrizes e bases da educação nacional. Disponível em: <http://www.planalto.gov.br/ccivil_03/ Leis/L9394.htm> Acesso em: 20 ago. 2019.

BRASIL. Ministério da Educação. Secretaria de Educação Profissional e Tecnológica. Catálogo Nacional de Cursos Técnicos. 3. ed. 2016. Disponível em: <http:// portal.mec.gov.br/docman/novembro-2017-pdf/77451-cnct-3a-edicao-pdf-1/file>. Acesso em: 20 ago. 2019.

BRASIL. Ministério da Educação. Secretaria de Educação Profissional e Tecnológica. Catálogo Nacional de Cursos Superiores de Tecnologia. 3. ed. 2016. Disponível em: <http://portal.mec.gov.br/index.php?option=com docman\&view=download\&alias=44501-cncst-2016-edcpdf\&category_slug=junho-2016-pdf\&Itemid=30192> . Acesso em: 20 ago. 2019.

CORDÃO, Francisco Aparecido. A LDB e a nova Educação Profissional. Boletim Técnico do Senac, v. 28, n. 1, p. $10-23,2018$

DOS SANTOS, Deribaldo Gomes; JIMÉNEZ, Susana Vasconcelos. Graduação Tecnológica no Brasil: aproximações críticas preliminares. Linhas Críticas, v. 15, n. 28, p. 171-185, 2009.

DIAS, Isabel Simões. Competências em Educação: conceito e significado pedagógico. Revista Semestral da Associação Brasileira de Psicologia Escolar e Educacional, v. 14, n. 1, p. 73-78, 2010.

FISCHER, Maria Clara Bueno; FRANZOI, Naira Lisboa. Formação humana e educação profissional: diálogos possíveis. Educação, Sociedade \& Culturas, v. 29, p. 33-49, 2009.

GIL, Antonio Carlos. Métodos e técnicas de pesquisa social. 6. ed. São Paulo: Atlas SA, 2008.

KAUARK, Fabiana da Silva; MANHÃES, Fernanda Castro; MEDEIROS, Carlos Henrique. Metodologia da pesquisa: um guia prático. Itabuna: Via Litterarum, 2010.

LOPEZ, Ricardo Vignotto.Como definir a melhor escala de avaliação de competências. 2016 Disponível em: <http://blogrh.com.br/como-definir-melhor-escala-de-avaliacao-de-competencias/>. Acesso em: 20 ago. 2019.

MACHADO, Lucília. O profissional tecnólogo e sua formação. Trabalho, Educação e Formação Profissional: perspectivas do capitalismo global. Campinas: Autores Associados, 2008.

MARINHO-ARAUJO, Claisy Maria; ALMEIDA, Leandro S. Abordagem de competências, desenvolvimento humano e educação superior. Psicologia: Teoria e Pesquisa, v. 32, p. 1-10, 2017.

MARINHO-ARAUJO, Claisy; RABELO, Mauro Luiz. Avaliação educacional: A abordagem por competências. Avaliação: Revista da Avaliação da Educação Superior, v. 20, n. 2, 2015.

SÃO PAULO. Centro Estadual de Educação Tecnológica Paula Souza. Projeto Pedagógico Curso Superior de Tecnologia em Análise e Desenvolvimento de Sistemas. 2013. Disponível em: <http://www.fatecsp.br/paginas/proj_ped_ads.pdf>. Acesso em: 20 ago. 19.

SÃO PAULO. Centro Estadual de Educação Tecnológica Paula Souza. Projeto Pedagógico Curso Superior de Tecnologia em Automação Industrial. 2011. Disponível em : <http://fatecsbc.edu.br/wp-content/uploads/2017/05/Projeto-Pedag\%C3\%B3gico-Automa\%C3\%A7\%C3\%A3o-Industrial-20152.pdf>. Acesso em: 20 ago. 19.

SÃO PAULO. Centro Estadual de Educação Tecnológica Paula Souza. Projeto Pedagógico Curso Superior de Tecnologia em Logística. 2016.Disponível em:<https:// www.fatecmogidascruzes.com.br/pdf/projeto_LOG. pdf>. Acesso em: 20 ago. 19.

SÃO PAULO. Centro Estadual de Educação Tecnológica Paula Souza. Plano de Curso Técnico Modular em Automação Industrial. 2016. Disponível em: <http:// www.etecgv.com.br/docs/planos_de_curso/automacao/ pc_automacao_modular_2semestre_2016.pdf>. Acesso em: 20 ago. 19.

SÃO PAULO. Centro Estadual de Educação Tecnológi- 
ca Paula Souza. Plano de Curso Técnico Modular em Desenvolvimento de Sistemas. 2017. Disponível em: <https://www.etecdeembu.com.br/assets/docs/planos/ Desenvolvimento-de-Sistemas-336_CS.pdf>. Acesso em: 20 ago. 19.

SÃO PAULO. Centro Estadual de Educação Tecnológica Paula Souza. Plano de Curso Técnico Modular em Logística. 2013. Disponível em: <http://www.etelg.com. $\mathrm{br} /$ paginaete/cursos/planos/planocurso/pc_logistica. pdf>. Acesso em: 20 ago. 19.

ZAKON, Abraham; DO NASCIMENTO, Jorge Luiz; SZANJBERG, Mordka. As funções dos cientistas, engenheiros, técnicos e tecnólogos. In: Congresso Brasileiro de Ensino de Engenharia, Brasília, Cd-Rom. 2003. 